\title{
Biofuel: A Scope for Reducing Global Warming
}

\section{Anantha Maharasi Ramakrishnan*}

Ph.D, Anna University, India

\begin{abstract}
The exponential increase in the global atmospheric temperature, global warming is mainly expedited by human interventions like deforestation and fossil fuel burning, pose threats to many natural resources, which in turn contribute for the deterioration of human health. Therefore, concerns for sustainment of life have led to growing worldwide interest in search for possible alternate ways for reducing the global warming. Biofuel productions have been considered as an alternate green solution for the replacement of fossil fuels. The present review is aimed to improve the focus towards the decrement of global warming as well as elucidating the methods and advantages of biofuel produced from various sources. And also, by which the technical barrier for efficient biofuel production could be overcome to mitigate global warming.
\end{abstract}

Keywords: Biofuel; Global warming; Greenhouse; Fluorinated gases

\section{Introduction}

Earth's atmosphere is important for the basic survivival of living organism and subsequent changes in the atmospheric temperature and pressure could lead to drastic changes, like melting ice bergs, rising sea level, volcanic eruptions and disruption of ecosystem. The recent report indicated that global average temperature has increased by $1^{\circ} \mathrm{F}$ since the beginning of $20^{\text {th }}$ century and is expected to increase by 2.5 to $10.4^{\circ} \mathrm{F}$ in the next 100 years and it is worthy to perceive that the last 30 years has been recorded as the warmest year in the past 1400 years in the Northern Hemisphere [1], insisting us for the immediate implementation of necessary actions. This increased temperature is influenced by diverse factors, with the most predominant being the greatest emissions of Greenhouse Gases [GHG], popularly known as a global warming.

GHG has the tendency to rotate and vibrate in a certain frequency unlike the other molecules such as nitrogen and oxygen, as a result which trap the energy from the similar frequency of light rays [2,3]. Typically the high energy short wavelength radiation reaches the earth surfaces from the sun, where half of the solar radiation is absorbed and the rest is converted to long wavelength heat energy for reflecting back to the space as an infrared rays [IFR]. Since the vibrating frequency of GHG matches with this IFR frequencies, which absorb the emitted heat energy from the earth surfaces and radiates back in all direction, in particular to the surface of Earth, thus maintaining the earth temperature around $33^{\circ} \mathrm{C}$. However when the amount of GHG such as Carbon dioxide $\left[\mathrm{CO}_{2}\right]$, Methane, Nitrous Oxide, Water vapor and Fluorinated gases increase immensely to extreme level, which can act as a blanket in the atmosphere and preventing the liberation of heat energy into the space resulting in global warming [2-6]. The amount of energy absorbed and emitted by this GHG is depends on the size, shape and geometry of the molecule and hence a shift in the concentration of these GHG in the earth atmosphere, majorly by human activities are greatly responsible for the present global warming effect.

\section{Carbon dioxide}

Carbon dioxide, one of the most potent green house gas, persists for more than 800 years, has its concentration increased enormously from $280 \mathrm{ppm}$ in late 1700 to $399 \mathrm{ppm}$ in 2014 according to the EPA [Environmental Protection Agency] report in USA [4] accounting for more than $75 \%$ of greenhouse effect. For the first time, a Swedish chemist Svante Arrhenius in 1896 gave a theory explaining that "doubling the amount of $\mathrm{CO}_{2}$ responsible for the increment of several degrees in the earth atmosphere" [5]. Generally, $\mathrm{CO}_{2}$ emission from natural sources like $28 \%$ from plant and animal's respiration and $28 \%$ from the soil respiration \& decomposition and like $42 \%$ from ocean with a small quantity being released by wild fire and volcanic eruptions and they had been offset by that natural source itself. However, in contrast $\mathrm{CO}_{2}$ emission from human activities like deforestation for the development of city \& factory, combustion of fossil fuel as well as industrial processes like cement production [7] have not been compromised by these existing sources. The combustion of fossil fuel for electricity and transportation, also subsequently discharges $\mathrm{CO}_{2}$ as a byproduct, accounts for $75 \%$ of total anthropogenic emission, and the amount varies with the type and carbon content of the fuel. It has been estimated that every tonne of coal produce around 2.5 tonne of $\mathrm{CO}_{2}$ while burning $[2,8,9]$ and finally accorded for 7 billion tons of $\mathrm{CO}_{2}$ per year that is increment of $1 \mathrm{ppm}$ per year. Besides, increased emission of $\mathrm{CO}_{2}$ warms the earth atmosphere which in turn triggers the release of more $\mathrm{CO}_{2}$ from ocean resulting in further increase the temperature, a process known as the positive feedback.

\section{Methane}

The second most powerful green house gas methane, account for the $9-14 \%$ of total green house gases and $15 \%$ of the greenhouse effect. Despite of short life span of decades, the heat trapping potential of methane is more potent than $\mathrm{CO}_{2}$, thus absorbing 84 times more heat with in first 2 years of its release. According to the EPA report, natural sources like wetlands, intestinal content of herbivorous animals, and decomposition of organic matter were responsible for $35 \%$ of global methane emission [10]. Decomposition of organic matters by anaerobic bacteria triggers the release of carbon dioxide and methane. The human activities responsible for methane releases are transport of fossil fuel [6,7], petroleum industry, oil and gas systems, burning of

*Corresponding author: Anantha Maharasi Ramakrishnan, Ph.D, Anna University, Chennai, India, Tel: +919500820272; E-mail: bioananthi.08@gmail.com

Receive November 16, 2015; Accepted November 29, 2015; Published December 08, 2015

Citation: Ramakrishnan AM (2015) Biofuel: A Scope for Reducing Global Warming J Pet Environ Biotechnol 7: 258. doi:10.4172/2157-7463.1000258

Copyright: (c) 2015 Ramakrishnan AM. This is an open-access article distributed under the terms of the Creative Commons Attribution License, which permits unrestricted use, distribution, and reproduction in any medium, provided the original author and source are credited. 
biomass from paddy fields, digestive and respiratory release of live stock as well as garbage decomposition in landfills. Among these prevalent anthropogenic releases, methane emission from fossil fuel industry account for the larger proportion $\sim 60 \%$ which is emitted during the process of coal mining and gas processing. Interestingly, biological and chemical reaction such as oxidation at tropospheric and stratospheric stage and soil absorption compensate the methane in atmosphere by converting it into less harmful product, nevertheless recent augmented releases of methane have not been counteracted by these sources [10]. The recent report alarmed that as a positive feedback increasing earth temperature to a degree; induce the methane release to several times from its natural source like arctic sea beds, permafrost and methane clathrate.

\section{Nitrous oxide}

Nitrous oxide, responsible for a trace amount of $5 \%$ of total greenhouse gasses, however, the most dangerous GHG as it has 300 times more heat trapping potential than $\mathrm{CO}_{2}$ as well as has extremely long life span of 120 years. Subsequently, the concentration of nitrous oxide has increased in a slow manner from 280 ppm in 1920 to 327 ppm in $2014[4,6]$. Natural sources like microbial activity in soil and ocean are the primary source for approximately $70 \%$ of nitrous oxide release. The most common sources of nitrous oxide is the usage of nitrogen containing synthetic fertilizers in agricultural field which is released by nitrifying bacteria during their degradation and also during the industrial production of nitric and adipic acid. In addition small amount could be released by fossil fuel combustion, biomass burning and atmospheric decomposition. The highest content of nitrate in the ground water can cause problem for human health. It could also create dead zones in the ocean.

\section{Water vapor}

According to the NASA report two/thirds of the gases trapped in the atmosphere is in the form of water vapor whose rate of evaporation and precipitation is chiefly regulated by temperature. Direct human activities have small influence on the increment of water vapor in the atmosphere, however indirectly; global warming increases the warming and moisture content of the air, which then absorbs the heat energy thus elevating the atmospheric temperature further. Although, it lasts for few days, water vapor has the capacity to double the green house effect created by $\mathrm{CO}_{2}$ and other GHG $[3,10]$.

\section{Fluorinated gases}

Even though present in a trace quantity, these gases are counted as an extremely powerful GHG as their heat absorbing potential is 1000 times more than that of carbon dioxide and the life span varies from few years to 1000 years. These gases differ from the rest of the GHG in their source, as it is synthesized by human activities. The major proportion of these gases includes Hydrofluorocarbon [HFC], Perfluorocarbon [PFC], sulfur hexafluoride $\left[\mathrm{SF}_{6}\right]$ and nitrogen trifluoride $\left[\mathrm{NF}_{3}\right]$. The predominant fluorinated gas HFC is mainly used in diverse industrial process such as a coolant in refrigerators, mobile air conditioners in cars and vehicles, as a blowing agent in foams formulation and as a propellant in aerosol spray to create liquid particles. HFC leaked into the atmosphere that account for global warming effect and dangerous cancer. PFC is synthesized as a byproduct in the aluminum production system and in the semi conductors manufacturing industry. $\mathrm{SF}_{6}$ is used as an insulator in electric transmission equipment and in the magnesium processing industry for preventing oxidation of magnesium. The amount of these fluorinated gases have escalated rapidly from $0 \%$ to $58 \%$ from 1990 to 2012 [11-14].

\section{Impacts of global warming}

The foremost dangerous effect of increasing temperature by even a mere increase of $1.5^{\circ} \mathrm{C}$ is sufficient for melting permafrost, a cryptic or frozen soil formed in the bottom layer of earth over the consecutive years. The major adverse effect of these melting is the release of an immense amount of sequestered carbon and methane that is 4 times more carbon than that released by recent human activities. It is speculated that by $220060 \%$ of northern hemisphere will melt and release 190 billion tons of carbon, causing dangerous irreversible changes. Classically, it also results in melting off of the Arctic sea beds of ice thereby stimulating release of methane from that.

The second most notable effect of global temperature increase is the conversion of sea ice into oceanic dark surfaces, thereby changing its innate nature of heat reflecting into increased heat trapping potential resulting in further increment of global temperature, ocean acidification, affecting the growth of aquatic life, biodiversity and the associated food web. In addition, rising sea level is also associated with increased storms, floods and cyclone that have negative impact on economic and human health [13].

Even though it has been identified early that increased $\mathrm{CO}_{2}$ stimulate the plant growth and biomass yield, recent evidence depicted that global warming adversely affect the $\mathrm{C} 3$ plants like Festuca vivipara [15]. For instance, high temperature impinge the seed germination and viability in the species like Juniperus communis, in addition to this, elevated $\mathrm{CO}_{2}$ affect the growth and yield by inhibiting Photosystem II in some species of Wedelia as well as by reducing Rubisco content in rice species. Moreover, elevated $\mathrm{CO}_{2}$ concentration and/or increased temperature trigger the susceptibility to pathogen mediated diseases in wheat and barley, which has been elaborated further in barley that by decreasing the amount of defense compound such as p-coumaroylhydroxyagmatine [16-20]. Moreover, increased $\mathrm{CO}_{2}$ reduce the nutritional composition of some plants such as deplete Vitamin C content in Lycopersicon esculentum [21].

The impact of global warming on human health is most enormous, such as the warmer temperature favors the growth and propagation of mosquito and so dramatically increasing life threatening mosquito borne diseases like dengue, chikuengunya as well as increases the vector borne and animal borne diseases. Strong potent and intense heat waves by global warming are responsible for an increase in the cardiovascular defects and associated deaths. Moreover air pollution due to the warm air, contributes for increased amounts of allergen which creates respiratory and lung diseases $[22,23]$.

\section{Biofuel}

As stated, most of the studies evidenced that burning of fossil fuels to generate electricity and to power the vehicles were the chief sources of global warming. With the recent advancement in the biological and biotechnological fields, it has been suggested that living organism can provide a sustainable source of fuel, without causing much global warming effect.

Types of biofuel: The hydrocarbon rich fuel from the biomass of biological organism is called as biofuel. The process of biofuel production can be classified into 3 types based on its source such as first generation biofuel from edible food crops, second generation biofuel from non-edible crops \& waste oil feed stock and third generation biofuel from algae. Based on the application of biofuel it is differentiated into bio ethanol, biodiesel and biogas [methane]. 
First generation biofuel: It is mainly synthesized from edible food crops, where bioethanol is synthesized from corn, sugar cane, maize; biodiesel from vegetable oils like soya bean oil, sunflowers oil, coconut oil and biogas from decomposition of organic material. Among these, corn was used to produce 15 billion gallon of ethanol in the United States recently and sugar cane is mainly used for the same purpose in Brazil. The production method of these is as follows: where starch, sugar, cellulose and/or any carbohydrate content of the plant organic matter is converted to glucose and then to alcohol or ethanol by microbial mediated enzymatic hydrolysis such as by Sacchromyces sps, Zymomonas and mold, which is followed by the distillation process to purify ethanol from the remaining biomass. Soyabean, the most preferable source of biodiesel has a high percentage of fatty acid that is converted to methyl ester by transesterification reaction. Transesterification is the reaction between the TAG [Triacyl glycerol] and alcohol to produce Fatty acids methyl esters [FAME] also known as biodiesel, this reaction also produce glycerol as a co-product. The reaction rate and yield of this reaction could be increased by the addition of methanol or any other alcohol and the final product serve as a best substitute for diesel and for cooking purpose [24,25]

Second generation biofuel: In order to produce biofuel from non edible crops and to increase its efficiency, second generation system has been accomplished with advanced techniques like biochemical and thermochemical methods that utilize the lignocellulosic and cellulosic component in addition to sugar and starch component of non edible food crops and waste vegetable oil. The pertinent crops for the production of biofuel are the oil plants like Jatropha and Eucalyptus, perennial grasses like miscanthus and switch grass. Biochemical processing of biomass follows 3 steps such as pretreatment either with ammonia or steam explosion for separation of the cellulosic content, which is converted to glucose by acid and/or enzymatic hydrolysis and then finally transformed into alcohol or ethanol by microbes mediated fermentation, followed by distillation to purify the end product. Thermal chemical method involves processing at higher temperature and pressure that includes direct combustion, gasification, liquefaction and pyrolysis. Direct combustion of biomass in the presence of air used to produce $\mathrm{CO}_{2}$ and water, and the released heat would be sufficient for domestic heating purposes. Gasification involves transformation of biomass into gaseous mixtures like $\mathrm{CO}, \mathrm{CO}_{2}, \mathrm{CH}_{4}, \mathrm{~N}_{2}$ and $\mathrm{H}_{2}$ known as syngas or producer gas by applying high temperature and the regulated flow of oxygen and/or steam, which may directly be employed in power generation system or treated with catalyst or at higher temperature to produce liquid fuel for transportation. Liquefaction is the conversation of biomass to liquid fuel in the presence of alkali or glycerin, followed by a reaction with solvent to reduce the viscosity of the fuel thus improving the yield. Pyrolysis involves the direct conversion of biomass into gaseous product by application of intense heat, and reactions carried out in the presence of inert gas like halogen and in the absence of oxygen. The eminent biofuel produced by these methods are Fischer Tropsch liquid, Dimethyl Ether and alcohol fuel [24-26].

Advantages of first and second generation biofuel: The bioethanol produced from cellulosic biomass directly used as fuel in a pure form or could be mixed with a petroleum for improved performance due to highest content of octane [27].

Bioethanol from sugar cane has significant amount of energy content, require less energy input and also considerable $90 \%$ reduction of $\mathrm{CO}_{2}$ emission such as $0.2-0.3 \mathrm{~kg} / \mathrm{CO}_{2}$ per liter ethanol compared to $2.8 \mathrm{Kg} / \mathrm{CO}_{2}$ per liter of gasoline, indeed bioethanol from sugar beet require more energy input and release $50-60 \%$ less amount of $\mathrm{CO}_{2}$ compared with gasoline [28].

Moreover, bioethanol releases trace amount of sulphur, in contrast to large amount by gasoline which is known for inducing acid rain and carcinogenic activity.

The production of ethanol from grass is more favorable because of the low fertilizer needs and the extensively increased yield.

It is possible to produce 145 liters of biodiesel from $\sim 150$ liters of waste vegetable oil that account for $88-95 \%$ energy content of the diesel and drastically reduce the $\mathrm{CO}_{2}$ emission by $80 \%$, sulfur and other pollutants in concerned amount $[27,28]$.

Disadvantages and the necessity for the third generation biofuel: The production of biodiesel from vegetable oil in first generation system is extremely expensive and entirely competes with the food source thereby increasing the cost of those food crops.

Combustion of bioethanol also increases the nitrous oxide level in the atmosphere as it reacts with the nitrogen in the atmosphere.

The reason for not attaining the success rate by second generation fuel is the conversion of biofuel from the lignocellulosic compound requires extensive \& expensive processing steps such as with enzyme cocktail, thus which is uneconomical for large scale production and important to note that grass is not suitable for the production of biodiesel [25,28].

Third generation biofuel: It encounters the demerits of past two generation system and having much advantages, such as highest content of oil in many algae strains such as more than $80 \%$ of its dry weight and the potential to grow extremely rapid, where some strains could double their biomass within 24 hours, with minimum requirements like water, sunlight and $\mathrm{CO}_{2}$ and also capable of growing in harsh conditions which is unfavorable for terrestrial plants, and is possible to culture in a wide scale over small area, with the added advantage that biofuel from algae to be non toxic, biodegradable and with favorable emission profile as it produces no Carbon monoxide, sulfur and unburned hydrocarbon $[29,30]$. Preferable option for producing biofuel like biodiesel from microalgae because which is found to be high oil content whereas bioethanol and biogas from macroalgae due to its richest carbohydrate content [31], despite it could be produced from alternate sources. The success rate of biofuel production lies in the selection of appropriate strains of high oil content and suitability to grow in a large scale with minimum requirement for example Botrycococcus, Chlorella sps etc widely used for producing biofuel.

\section{Biodiesel from microalgae}

There are 3 available techniques for cultivating microalgae in a large scale includes an open system, performed in an open ponds which is prone to contamination and evaporation of water, thus resulting in less productivity, however suitable for cultivating algae with a lower content of oil, a second closed system with highly regulated temperature and less chance of contamination but expensive than open system and the last but the most preferred technique is the photo bioreactors which is a closed container, illuminated by solar or artificial light and temperature regulated with continual stream of water containing essential nutrients, air and $\mathrm{CO}_{2}$, thus improving the overall yield of biofuel. The cultivated algae is harvested by sedimentation, filtration, centrifugation or membrane filtration and then directly dehydrated to remove the moisture content at lower temperature and higher pressure such as $300^{\circ} \mathrm{C}, 10 \mathrm{MPa}$ [32]. These are followed by significantly important 
drying steps, which determine the yield and then costly process of oil/ triglycerides extraction technique that includes mechanical methods like expeller press or with ultrasonic assisted extraction and chemical methods such as hexane solvent and soxhelt extraction or by using cell wall digesting enzymes. Similarly, transesterification process is used to convert triglycerides to FAME /biodiesel with glycerol as a byproduct, where the reaction rate is increased in the presence of catalyst like acid or base such as $\mathrm{NaOH}$ or $\mathrm{KOH}$. The yield of biodiesel and sustainability depends on the selection of appropriate strains and methods of oil extraction such as oil with high content of saturated fatty acid possibly produces high stable biodiesel because, the presence of poly unsaturated fatty acid are prone to oxidation and alkali based transesterification process provides high ratio of biomass conversion [33-35]. A recent technique called hydrothermal liquefaction, produce biodiesel at low temperature $\sim 350^{\circ} \mathrm{C}$ and high pressure $20 \mathrm{MPa}$ which does not required drying or dehydration. The productivity and yield could be improved by the addition of carbon dioxide and the growth rate of algae increased by the addition of nitrogen [36].

\section{Bioethanol from macro algae}

The production of bioethanol \& biogas from macro algae like red, green, brown algae such as Gelidium amansii, Laminaria hyperborean is quite a feasible process, because of the significant high quantities of carbohydrate and considerably limited amount or completely absence of lignin which is a hindrance in terrestrial plants for fermentation and degradation process and in addition some strains of micro algae like chlorella vulgaris also used for producing bioethanol because of its increased lipid content. Among the three macroalgae, brown algae act as an excellent feedstock because of the high amount of carbohydrate over the other two. Similar technique, like dehydration, direct combustion, gasification and pyrolysis is mainly used for converting bioethanol and biogas from biomass, which can be categorized into dry and wet process. Dry methods of bioethanol production includes, removal of water from macro algae which is an efficient and energy intensive process, followed by direct combustion, gasification in the presence of oxygen or pyrolysis in the absence of oxygen for decomposing the organic biomass and to produce the syngas which is converted to bioethanol in the presence of catalyst. Eventually, wet methods use hydrothermal liquefaction for converting biomass into ethanol by applying low temperature and high pressure in the presence of catalyst, which is again converted to bioethanol or biobutanol by microbial mediated fermentation as briefed earlier. Compared to bioethanol, there has been much more interest towards the production of biobutanol from macroalgae because of its increased energy efficiency for transportation [35,37-40].

\section{Biogas production}

Anaerobic degradation of macro algae biomass results in the production of biogas [methane] that is directly used to produce electricity and for transportation purposes. Primarily, the carbohydrate content of the biomass is converted to alcohol and carboxylic acid and earlier is converted to acetate, hydrogen and $\mathrm{CO}_{2}$ by acetogenic bacteria. The methanogenic bacteria react with these products and finally transform these into methane and $\mathrm{CO}_{2}$. Typically, overall process can be divided into single stage and two phase digesters, the production cost and the yield is favorable in two phase system, as in that system biomass and the substrate is pre enriched. The yield of bioethanol and biogas is depending on the amount of carbohydrate and the type of fermenting and anaerobic microbes used, respectively. Moreover, the reaction rate is mainly impeded by high concentration of metal, nitrogen and sulfur, in spite of its catalyst activity at lowest concentration. For instance strain from polluted area interfere with the fermentation and methane production at high concentration thereby considerable attention have to be paid during the selection of macroalgae species $[35,41,42]$.

Advantages and disadvantages: In addition to those mentioned above, algae has the potential to grow in a relatively short span of time ranging from few days to months compared to years of growth required for terrestrial plants, and also this is a climate independent process. It is most fascinating to know that algae consumes more amount of $\mathrm{CO}_{2}$ for their growth comparatively, which further reduces the atmospheric $\mathrm{CO}_{2}$ level. However, the major drawback of algae based biofuel is the productivity cost for culturing and extraction. For instance, algal culturing with photo bioreactor requires heat exchanger for cooling during the day time and for regulation of the temperature during the night time. In addition, high cost is also required for cell wall disruption for harvesting algal biomass and oil [41,43].

\section{Recent trends in biofuel technology}

In order to reduce the cost effect of enzymatic hydrolysis of algal cell wall disruption and degradation, recent approaches like membrane disruption by algicidal substances have been improved which is secreted either from bacteria or viruses or algae such as from the species of Flammeovirga, Pseudomonas, Alteromonas, Pseudoalteromonas, Silibacter, Aeromonas, Clostridium, paramecium and chlorella viruses etc. These organisms are co-cultured with micro or macro algae for producing strain and cell-wall specific enzymes such as carbohydrases, proteases, pore forming enzymes etc for the disruption of cell membrane [44].

The production of algae from biofuel could be encouraged by coupling with waste water treatment or phycoremediation, the reason behind this are the algae have the potential to use carbon from waste gas $\mathrm{CO}_{2}$, ability to remove toxic components, possibility of utilizing the nitrogen and phosphorous as a nutrient source for the production of biomass which is present enormous amount in waste water from domestic and aquaculture, therefore efficiently improve the economic outlook of production systems $[45,46]$. Recently, it has been depicted by Prajapati et al that co-cultivation of algae with livestock waste water and followed by digestion with cattle bung promoted the biomass and bioenergy production [47].

Lipid Droplets $[\mathrm{LD}]$ is an organelle contain neutral lipid core and phospholipid membrane which is present in bacteria, yeast and green algae which have been drawn increased attention recently for the production of biofuel especially biodiesel, owing to the conversion \& storage of high amount TAG in LD from their biomass. Green algae have the ability to produce 100 fold more oil than the plant as well as bacteria such as Rhodococcus opacus has been identified to store $87 \%$ of TAG in their dry weight [48]. Nonetheless, further research in this LD organelle and algicidal organism will greatly improve the third generation biofuel.

\section{Conclusion}

The world frightening problem have long been recognized as a Global warming, affects the basic natural resources like land, water and air thus results in long lasting irreversible changes like respiratory gas for human and other organisms will be depleted in a short span of time. The recent report in U.S Energy Information administration estimated that 2.4 billion metric tons of carbon released into the atmosphere per year for electricity production, as well as average passenger car produces 11,450 pounds of $\mathrm{CO}_{2}$ every year and almost 246 million 
cars in U.S alone, this amount would be unforeseeable globally. But, absorption of carbon through natural resources like plants and ocean are lesser and this is further decreased by recent anthropogenic global change and deforestation. It is estimated that almost 9.9 billion US tons of $\mathrm{CO}_{2}$ released per year in USA, whereas ocean can absorb at the maximum of 6.6 billion USA tons per year and a tree can absorb 48 pounds of the $\mathrm{CO}_{2}$ per year, thus the natural resources is not compatible with the surplus amount of greenhouse gases. Typically, biofuel produce lesser amount of $\mathrm{CO}_{2}$ such as, diesel from heating oil and natural gas release 161 pounds and 117 pounds of $\mathrm{CO}_{2}$ respectively compared to 228 pounds from coal fuel per BTU [British Thermal Unit]. Most importantly, biodiesel and bioethanol emit and absorb almost equal or more amount of $\mathrm{CO}_{2}$ during production, in particular with algae biofuel, thus which is not increasing the global $\mathrm{CO}_{2}$ level. In culmination, compared to 3 systems, biofuel from algae would be a most sustainable alternate source of energy due to the several advantages to name a few not having impact on food web, land usage and other living organism and drastically reduce the GHG emission. Although, these technologies are still in the early developmental stage, further research in this field is prerequisite to transform this into reality.

\section{Future Perspectives}

- More than 10000 species of algae have not been identified yet [29], the identification and characterization of these species may provide a more suitable strain for efficient biofuel production, and also more light needed to be shed on to the processing and culturing methods which regulates growth, biomass production and yield of biofuel.

- The major bottleneck of algal biofuel is its less stability, quality and expensive; Genetic Engineering approach of fatty acid metabolic pathway and system biology approach will facilitate improved growth, biomass production, stability in a feasible cost, thereby biofuel from algae would provide an exciting solution to accomplish the fuel requirement and to compete with petroleum industry.

- Intriguingly, in recent times algae are cultivated in tubes in highways which are proficiently remove the $\mathrm{CO}_{2}$, majorly released by vehicles as well as convert that into useful energy by sun light mediated photosynthesis. It would be possible in future to produce algae mediated biofuel in coupled with this technique by promoting research in this area.

\section{References}

1. Climate change (2014) Synthesis Report summary for policymakers.

2. Steen M (2001) Greenhouse Gas Emissions from Fossil Fuel Fired Power Generation Systems. European Commission Joint Research Centre.

3. Green House Gases. Why some gases are greenhouse gases, but most aren't and some are stronger than others.

4. Environmental Protection Agency (2015) Climate change indicators in the United States: Atmospheric concentration of Greenhouse Gases.

5. Flint K (2011) Global Warming: The Hottest debate of the decade. Dartmouth Undergraduate Journal of science.

6. Ramanathan V (1997) Trace-Gas Greenhouse effect and Global warming: Underlying Principles and Outstanding Issues. Volvo Environmental Prize Lecture.

7. Hiroki H (2005) Life cycle GHG emission analysis of power generation systems: Japanese case. Elsevier Energy 30: 2042-2056.

8. Bradshaw J, Chen Z, Garg A, Gomez D, Hans-Holger Rogner, et al. (2005) Sources of $\mathrm{CO}_{2}$. IPCC special report on carbon dioxide capture and storage.

9. Sawayama S, Inoue S, Dote $\mathrm{Y}$ and Yokoyama $\mathrm{S} Y(1995) \mathrm{Co}_{2}$ Fixation and oil production through microalgae. Energy Conversion and Management 66 729-731.

10. A more potent greenhouse gas than carbon dioxide, methane emissions will leap as Earth warms (2014) Princeton University Science Daily.

11. Christian NJ, Boardman B, Ayub Osman Julia Vowles and Jane Palmer Methane UK: Climate science of Methane. Environmental Change Institute, Osford University: 14-23.

12. James Frank (2015) Water vapor is the most powerful greenhouse gases. Skeptical Science article.

13. Gschrey B, Schwarz W (2009) Projections of global emission of fluorinated greenhouse gases in 2050

14. Schwaab K, Dettling F, Bernhardt, Elsner C, Sartorius R, et al. (2008) Fluorinated GreenHouse Gases in Products and Processes: An evaluation of Technical Measures to Reduce Greenhouse Gas Emission. German Federal Environmental Agency Germany.

15. Xie H, Liu K, Sun D, Wang Z, Lu X, et al. (2015) A field experiment with elevated atmospheric $\mathrm{CO}_{2}$-mediated changes to $\mathrm{C} 4$ crop-herbivore interactions. Sci Rep. 18: 13923.

16. Váry Z, Mullins E, McElwain JC, Doohan FM (2015) The severity of wheat diseases increases when plants and pathogens are acclimatized to elevated carbon dioxide. Glob Chang Biol.

17. Mikkelsen BL, Olsen CE, Lyngkjær MF (2015) Accumulation of secondary metabolites in healthy and diseased barley, grown under future climate levels of $\mathrm{CO}_{2}$, ozone and temperature. Phytochemistry 118: 162-173.

18. Gruwez R, De Frenne P, De Schrijver A, Leroux O, Vangansbeke P, et al (2014) Negative effects of temperature and atmospheric depositions on the seed viability of common juniper (Juniperus communis). Ann Bot 113: 489-500.

19. Song L, Chow WS, Sun L, Li C, Peng C (2010) Acclimation of photosystem II to high temperature in two Wedelia species from different geographical origins: implications for biological invasions upon global warming. J Exp Bot 61 : 4087-96.

20. Adachi M, Hasegawa T, Fukayama H, Tokida T, Sakai H, et al. (2014) Soil and water warming accelerates phenology and down-regulation of lea photosynthesis of rice plants grown under free-air $\mathrm{CO}_{2}$ enrichment (FACE). Plant Cell Physiol 55: 370-80.

21. Khan I, Azam A, Mahmood A (2013) The impact of enhanced atmospheric carbon dioxide on yield, proximate composition, elemental concentration, fatty acid and vitamin $\mathrm{C}$ contents of tomato (Lycopersicon esculentum). Environ Monit Assess 185: 205-14.

22. Wiman, Bo LB (2011) Effects of global warming on environmental pollution: An area with many knowledge gaps. Climate change, Human system and policy.

23. Snow M, Snow R (2015) The impact of climate change on Human Health Journal of Climatology and Weather Forecasting 3:1.

24. Naik SN, Vaibhav V Goud, Prasant K Rout, Ajay K Dalai (2010) Production of first and second generation biofuels: A comprehensive review. Renewable and Sustainable Energy Review 14: 578-297.

25. Larson ED (2008) Biofuel production technologies: status, prospects and implications for trade and development. United National conference on Trade and development, New York, USA.

26. Singh SP, Singh D (2010) Biodiesel production through the use of different sources and characterization of oils and their esters as the substitute: A review. Renewable and Sustainable Energy Review 14: 200-216.

27. http://www.greenfacts.org/en/biofuels/l-3/1-definition.htm\#0p0-

28. Biofuel Production (2007) IEA energy Technology Essentials.

29. Shalini Rajvanshi, Mahendra Pal Sharma (2012) Microalgae: A Potential Source of biodiesel. Journal of Sustainable Bioenergy System 2: 49-59.

30. Manikandan G, Senthil Kumar P, Prakalathan R (2014) Comparison of Biodiesel Production from Macro and Micro Algae. International Journal of ChemTech Research 6: 4143-4147.

31. Moheimani NR, Mchenry MP, Mehrani P (2013) Microalgae Biodiesel and Macroalgae Bioethanol: The solar conversion Challenge for Industria Renewable fuels. Book Natural and Artificial Photosynthesis: The Solar Conversion Challenge for Industrial Renewable Fuels. 
32. Anders S Carlsson, Jan B van Beilen, Ralf Moller, David Clayton (2007) Micro and Macro Algae: Utility for Industrial applications. CPL Press UK

33. Carvalho J, Ribeiro A, Castro J, Vilarinho C, Castro F (2011) Biodiesel production by microalgae and macroalgae from north littoral portuguese coast, Wastes: solutions, Treatments and oppurtunities $1^{\text {st }}$ international conference.

34. Dragone G, Fernandes B, Antonio AV, Jose AT (2010) Third generation Biofuel from microalgae. Current Research, Technology and Education Topics in Applied Microbiology and microbial biotechnology.

35. Behera S, Singh R, Arora R, Sharma NK, Shukla M, et al. (2014) Scope of algae as third generation biofuels. Front Bioeng Biotechnol 2: 90.

36. Douglas C Elliott, Todd R Hart, Andrew J Schmidt, Gary G Neuenschwander, Leslie J Rotness, et al. (2013) Process development for hydrothermal liquefaction of algae feedstocks in a continuous- flow reactor. Elsevier Algal Research 2: 445-454.

37. Najafi G, Ghobadian B, Talal FY (2011) Algae a sustainable energy source for biofuel production in Iran: A case study. Renewable and Sustainable Energy Review 15: 3870-3876.

38. Lesson 6 (2014) How algae can be used to produce Biofuel-biomara.

39. Hannon M, Gimpel J, Tran M, Rasala B, Mayfield S (2010) Biofuels from algae: Challenges and Potential. Biofuels 1: 763-784.

40. Dragone G, Fernandes B, Antonio AV, Jose AT (2010) Third generation Biofuel from microalgae. Current Research, Technology and Education Topics in Applied Microbiology and microbial biotechnology.
41. Suutari M, LEskinen E, Fagerstedt K, Kuparinen J, Kuuppo P, et al. (2015) Macroalgae in biofuel production. Phycological Research 63: 1-18.

42. Milledge JJ, Smith B, Dyer PW, Harvey P (2014) Macroalgae- Derived Biofuel: A Review of Methods of Energy Extraction from Seaweed Biomass. Energies 7: 7194-7222.

43. Zhiyou Wen, Michael B Johnson (2009) Microalgae as a Feedstock for Biofue Production. Virginia Cooperative Extension Publication 442-886.

44. Demuez M, González-Fernández C, Ballesteros M (2015) Algicidal microorganisms and secreted algicides: New tools to induce microalgal cell disruption. Biotechnol Adv 33: 1615-1625.

45. Prajapati SK, Kaushik P, Malik A, Vijay VK (2013) Phycoremediation coupled production of algal biomass, harvesting and anaerobic digestion: possibilities and challenges. Biotechnol Adv 31: 1408-25.

46. Guo Z, Liu Y, Guo H, Yan S, Mu J (2013) Microalgae cultivation using an aquaculture wastewater as growth medium for biomass and biofuel production. J Environ Sci 1: S85-86.

47. Prajapati SK, Choudhary P, Malik A, Vijay VK (2014) Algae mediated treatment and bioenergy generation process for handling liquid and solid waste from dairy cattle farm. Bioresour Technol 167: 260-268

48. Liu Y, Zhang C, Shen X, Zhang X, Cichello S, et al. (2013) Microorganism lipid droplets and biofuel development BMB Rep 46: 575-81. 